\title{
Serum lactate dehydrogenase level in pre-eclampsia and its correlation with maternal and fetal outcome
}

\author{
Niyanta P. Vyas ${ }^{1}$, Nandini Gopalakrishna ${ }^{2 *}$, Jessica Fernandes ${ }^{2}$
}

\author{
${ }^{1}$ Department of Obstetrics and Gynecology, Chirayu Hopsital, Dahod, Gujarat, India \\ ${ }^{2}$ Department of Obstetrics and Gynecology, M. S. Ramaiah Medical College and Hospitals, Bangalore, Karnataka, India
}

Received: 10 October 2021

Revised: 15 October 2021

Accepted: 25 October 2021

\section{*Correspondence:}

Dr. Nandini Gopalakrishna,

E-mail: nandinigopalakrishna@gmail.com

Copyright: $($ ) the author(s), publisher and licensee Medip Academy. This is an open-access article distributed under the terms of the Creative Commons Attribution Non-Commercial License, which permits unrestricted non-commercial use, distribution, and reproduction in any medium, provided the original work is properly cited.

\section{ABSTRACT}

Background: Hypertensive disorders are the most common medical disorders during pregnancy. It increases maternal and perinatal morbidity and mortality. The incidence is 7 to $10 \%$. Identifying high risk patients and close monitoring can reduce the complications. Lactate dehydrogenase is a useful biochemical marker and can be used to evaluate maternal complications like Disseminated intravascular coagulation (DIC), HELLP syndrome (Haemolysis, elevated liver enzymes and lowered platelets), pulmonary edema, renal failure and fetal complications like Fetal growth restriction (FGR) APGAR score $\leq 7$ at $5 \mathrm{~min}$ and Neonatal intensive care unit (NICU) admissions. The objective of this study was to estimate serum Lactate dehydrogenase levels (LDH) in pre-eclampsia patients and study the correlation between increased LDH levels and maternal and fetal outcome.

Methods: It was a prospective study from October 2015 to May 2017 at M. S. Ramaiah medical college and hospitals, Bangalore.

Results: The incidence of maternal and foetal complications was increased with higher serum LDH levels. With serum LDH >than $600 \mathrm{IU} / 1$ the incidence of HELLP syndrome, DIC, pulmonary edema was statistically significant. It also correlated with increased creatinine levels and decreased platelets with $\mathrm{p}$ value $<0.001$. The foetal complications including FGR NICU admission and Apgar score $<7$ at 5 min was statistically significant. The liver enzymes and serum creatinine correlated with increased LDH levels.

Conclusions: Maternal and foetal complications are increased with raised LDH levels, and it can be used as a biochemical marker to achieve a better outcome.

Keywords: Abruptio placenta, Disseminated intravascular coagulation, Foetal growth restriction, HELLP syndrome, Lactate dehydrogenase, Pre-eclampsia

\section{INTRODUCTION}

Hypertensive disorders complicate $5-10 \%$ of all pregnancies and together they are one family of the deadly triad- along with haemorrhage and infection-that contribute greatly to maternal morbidity and mortality. Of these disorders, the preeclampsia syndrome either alone or superimposed on chronic hypertension is the most dangerous. ${ }^{1}$ Although the precise aetiology of preeclampsia is not clear, defective placentation and endothelial dysfunction are considered the core features of preeclampsia. $^{2}$

Many theories have suggested that endothelial dysfunction caused by factors released from ischaemic placenta, may be a factor for disease pathogenesis. ${ }^{3}$ 
The complications of preeclampsia include: abrupt placentae, HELLP syndrome, DIC, liver failure, renal failure, retinal detachment and cerebral haemorrhage. The foetal complications include FGR, Intrauterine foetal demise, Apgar score $<7$ at 5 min and NICU admissions.

In the absence of effective screening modalities, clinical risk factors can help us to be vigilant. ${ }^{4}$ Early detection of pre-eclampsia is imperative and non-invasive diagnostic methods based on biomarkers holds promise. ${ }^{5}$ Lactate dehydrogenase (LDH) is a glycolytic enzyme involved in the reversible conversion of pyruvate to lactate when absolute or relative anoxemia is present. ${ }^{6}$ Elevated levels of LDH indicate intracellular death and leakage of enzyme from the cell. High levels were found in association with severe preeclampsia.

LDH is a useful biochemical marker that reflects the severity of preeclampsia and the occurrence of complications of preeclampsia. ${ }^{7}$ Serum LDH estimation and monitoring may help to decrease complications in preeclampsia and thereby help in improving maternal and foetal outcome.

The purpose of this study was to analyse if serum LDH levels can be used as a prognosticator in the management of preeclampsia.

\section{Objectives}

The objectives of this study were (a) to estimate serum LDH levels in preeclampsia patients; and; (b) to study the correlation between increased serum LDH levels and maternal and foetal outcome.

\section{METHODS}

This was a prospective study at the department of obstetrics and gynecology M. S. Ramaiah medical college and Hospitals from October 2015-May 2017.

All pregnant women with BP recording of $>140 / 90 \mathrm{mmHg}$ and proteinuria after 20 weeks of gestation attending antenatal clinic and those who were admitted at Ramaiah Hospitals were enrolled. The sample size was 115 .

The lab method used was quantitative measurement of serum LDH was done by ELISA kit based on the principal that it catalyses the reaction between pyruvate and NADH. Based on LDH level, the patients were divided into two groups. Group 1 with serum LDH value $<600 \mathrm{IU} / 1$ and group 2 with serum LDH >600 IU/l. Incidence of maternal complications like abruption placentae, eclampsia, HELLP syndrome, DIC, liver failure, renal failure, retinal detachment and cerebral haemorrhage were studied Incidence of foetal complications like FGR, Intra Uterine foetal demise (IUFD), Apgar score $<7$ at 5 min and NICU admission were studied in each group.

\section{Inclusion criteria}

All patients with gestational age $>20$ weeks and BP $>140 / 90 \mathrm{mmHg}$ along with proteinuria were included in the study.

\section{Exclusion criteria}

High BP recordings before 20 weeks gestation were excluded from the study.

Pre-existing medical conditions such as- diabetes mellitus, renal disorders, liver disorders, connective tissue disorders, cardiac disease, musculoskeletal disorders, haemolytic anaemia, epilepsy and thrombophilia.

\section{Statistical analysis}

Descriptive and inferential statistical analysis was carried out in the present study. Results on continuous measurements are presented on mean \pm SD (min-max) and results on categorical measurements are presented in number (\%). Significance is assessed at 5\% level of significance. The following assumptions on data was made.

Chi square/Fischer exact test was used to find the significance of study parameters on categorical scale between the two groups. Non-parametric setting for qualitative data analysis and Fischer exact test used when cell samples were small.

The statistical software namely SPSS 18.0 , and $\mathrm{R}$ environment version 3.2.2 were used for the analysis of the data and Microsoft word and excel have been used to generate graphs and tables.

\section{RESULTS}

Age, gravidity, period of gestation, mode of delivery, maternal and fetal complications were studied. Between October 2015 to May 2017, all patients with preeclampsia who fulfilled the inclusion criteria were studied.

In our study $43.9 \%$ were between $19-24$ years of age and $36.8 \%$ were between $25-29$ years. This showed that $80.7 \%$ were below 30 years of age. Unbooked patients accounted for $60.5 \%$ and booked patients accounted for $39.5 \%$. Ours being a tertiary center we have a larger number of unbooked referrals.

It was seen that hypertension was more prevalent among Primigravidae which accounted for $65.8 \%$.

It was seen that $36 \%$ were between $28-32$ weeks of gestation and $37.7 \%$ were between 33-36 weeks.

Antepartum eclampsia accounted for $11.4 \%$, HELLP syndrome $8.7 \%$ and abruption $7.9 \%$ of the cases. 
The mode of delivery was LSCS in $51.8 \%$ and vaginal delivery in $48.2 \%$. Serum LDH levels $>600 \mathrm{IU} / 1$ was seen in $16.7 \%$ of the cases. It was seen that, $49.1 \%$ of the newborns were $<1.5 \mathrm{~kg}$. Most of the cases were induced before term in order to prevent maternal complications. FGR was seen in $39.1 \%$ and NICU admissions were noted in $54.4 \%$ of study population. With increased serum LDH levels, maternal complications were seen to be higher. The overall incidence of HELLP syndrome in the present study was $8.7 \%$ and serum LDH was elevated in $73.3 \%$ of this population. This correlated with $\mathrm{p}$ value $<0.001$. The overall incidence of DIC was $1.7 \%$ with $15.8 \%$ of this population having elevated $\mathrm{LDH}$, this corresponded with $\mathrm{p}$ value $<0.004$ significant. The overall incidence of pulmonary edema in this study was $2.6 \%$ with $10.5 \%$ of this population having elevated LDH levels. This corresponded with $\mathrm{p}$ value $<0.072$ significant.

Table 1: Age distribution.

\begin{tabular}{|lll|}
\hline Age in years & Number of patients $(\mathbf{N}=\mathbf{1 1 5})$ & Percentage $(\%)$ \\
\hline $\mathbf{1 9 - 2 4}$ & 50 & 43.9 \\
\hline $\mathbf{2 5 - 2 9}$ & 43 & 36.8 \\
\hline $\mathbf{3 0 - 3 4}$ & 16 & 14.0 \\
\hline $\mathbf{3 5}-\mathbf{4 0}$ & 6 & 5.3 \\
\hline
\end{tabular}

Table 2: Booked verses unbooked.

\begin{tabular}{|lll|}
\hline Type & Number of patients $(\mathbf{N}=115)$ & Percentage $(\%)$ \\
\hline Booked & 46 & 39.5 \\
\hline Unbooked & 69 & 60.5 \\
\hline
\end{tabular}

Table 3: Gravidity distribution.

\begin{tabular}{|lll|}
\hline Gravidity distribution & Number of patients $(\mathbf{N}=\mathbf{1 1 5})$ & Percentage $(\%)$ \\
\hline Primigravida & 75 & 65.8 \\
\hline Multigravida & 40 & 34.2 \\
\hline
\end{tabular}

Table 4: POG of patients.

\begin{tabular}{|lll|}
\hline POG (in weeks) & Number of patients $(\mathbf{N}=\mathbf{1 1 5})$ & Percentage $(\boldsymbol{\%})$ \\
\hline $\mathbf{2 8 - 3 2}$ & 41 & 36 \\
\hline $\mathbf{3 3 - 3 6}$ & 43 & 37.7 \\
\hline $\mathbf{3 7 - 4 0}$ & 31 & 26.3 \\
\hline
\end{tabular}

Table 5: Maternal complications.

\begin{tabular}{|lll|}
\hline Maternal complications & Number of patients $(\mathbf{N}=\mathbf{1 1 5})$ & Percentage $(\%)$ \\
\hline HELLP syndrome & 10 & 8.7 \\
\hline DIC & 2 & 1.7 \\
\hline Pulmonary edema & 3 & 2.6 \\
\hline Abruption & 9 & 7.9 \\
\hline Antepartum eclampsia & 13 & 11.4 \\
\hline
\end{tabular}

Table 6: Mode of delivery.

\begin{tabular}{|lll|}
\hline Mode of delivery & Number of patients $(\mathbf{N}=115)$ & Percentage $(\%)$ \\
\hline Vaginal delivery & 56 & 48.2 \\
\hline Lower segment caesarean section (LSCS) & 59 & 51.8 \\
\hline
\end{tabular}

Table 7: Serum LDH levels.

\begin{tabular}{|lll|}
\hline Serum LDH levels & Number of patients & Percentage $(\%)$ \\
\hline$<\mathbf{6 0 0}$ & 96 & 83.4 \\
\hline$>\mathbf{6 0 0}$ & 19 & 16.7 \\
\hline
\end{tabular}


Table 8: Birth weight.

\begin{tabular}{|lll|}
\hline Birth weight $(\mathrm{kg})$ & Number of neonates & Percentage $(\%)$ \\
\hline $\mathbf{1 . 5}$ & 56 & 49.1 \\
\hline $\mathbf{1 . 5 - 2 . 5}$ & 49 & 42.1 \\
\hline $\mathbf{2 . 5}$ & 10 & 8.8 \\
\hline
\end{tabular}

Table 9: Fetal outcome.

\begin{tabular}{|lll|}
\hline Fetal outcomes & Number $(\mathbf{N}=115)$ & Percentage $(\%)$ \\
\hline FGR & 45 & 39.1 \\
\hline NICU admissions & 62 & 54.4 \\
\hline IUFD & 08 & 7 \\
\hline Apgar $\leq 7$ at 5 min & 46 & 40.4 \\
\hline Still birth & 08 & 7 \\
\hline Meconium stained liquor & 36 & 31.6 \\
\hline RDS & 15 & 13.2 \\
\hline Neonatal death & 08 & 7 \\
\hline Stable & 37 & 32.2 \\
\hline
\end{tabular}

Table 10: Complications in relation to serum LDH levels.

\begin{tabular}{|c|c|c|c|c|c|}
\hline \multirow{3}{*}{ Complications } & \multicolumn{4}{|c|}{ Serum LDH } & \multirow{3}{*}{$\begin{array}{l}\text { P value (Fisher } \\
\text { exact test) }\end{array}$} \\
\hline & \multicolumn{2}{|c|}{$<600$ IU/l } & \multicolumn{2}{|c|}{$>600 \mathrm{IU} / \mathrm{l}$} & \\
\hline & $\mathbf{N}$ & $\%$ & $\mathbf{N}$ & $\%$ & \\
\hline HELLP syndrome & 0 & - & 10 & 73.7 & $<0.001$ significant $* *$ \\
\hline DIC & 0 & - & 2 & 15.8 & 0.004 significant* \\
\hline Pulmonary edema & 1 & 1.1 & 2 & 10.5 & 0.072 significant $_{+}$ \\
\hline Abruption & 6 & 6.3 & 3 & 15.8 & 0.171 insignificant \\
\hline
\end{tabular}

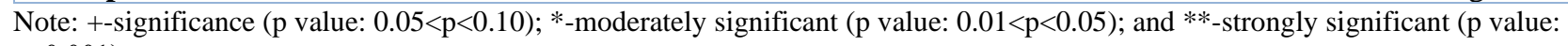
$\mathrm{p} \leq 0.001)$.

\section{DISCUSSION}

Pre-eclampsia is considered to be an idiopathic multisystem disorder that is specific to human pregnancy. ${ }^{8}$ Preeclampsia may be life threatening for both mother and child increasing both foetal and maternal morbidity and mortality. ${ }^{8}$ The haemodynamic alteration, activation of the coagulation cascade with micro thrombi results in perinatal as well as maternal complications. ${ }^{9}$

Early prediction and management will prevent complications. The timing of delivery is critical.

In recent times, several research studies have suggested serum LDH as a potential indicator of preeclampsia and serum LDH levels have been observed to increase with the severity of the ailment. ${ }^{3,8,11}$

The multiorgan dysfunction in severe preeclampsia caused by vascular endothelial damage including maternal liver, kidney, lungs, nervous system, blood and coagulation system will lead to excessive LDH levels in serum due to cellular dysfunction. ${ }^{14}$

Young age and primigravida are well known risk factors for developing pre-eclampsia. ${ }^{16}$
Numerous risk factors for preeclampsia have been suggested but only some have been established in multivariant models that permit simultaneous control for possible cofounders. ${ }^{17}$

The neonatal outcome has been linked to neonatal intensive care facilities and gestational age at birth. ${ }^{18}$

Preeclampsia and foetal growth restriction remain an important cause of morbidity and mortality. ${ }^{19}$

Placental growth factor (PlGF) is a pro angiogenic factor and from as early as 11-13weeks gestation, low levels are associated with the later development of pre-eclampsia. sFlt-1 (Soluble fms-like tyrosine kinase 1) is antiangiogenic and levels elevated as much as 5 weeks prior to the clinical onset of the disease. Both have been evaluated as diagnostic tests but neither has sufficient sensitivity to be of use in clinical practice. ${ }^{20}$

In the present study, age factor did not have any significant correlation, though majority were less than 30 years. The unbooked patients in our hospital accounted for $60.5 \%$, indicating that majority were referrals (Table 2). Primigravidae accounted for $65.8 \%$ (Table 3 ). This was similar to the study by Hak et al where primigravida accounted for $74 \% .^{3}$ 
In our study, $26.3 \%$ were between $37-40$ weeks of gestation (Table 4). In a study done by Doddamani et al $53 \%$ were term gestation. ${ }^{13}$

The incidence of severe preeclampsia was $64 \%$ in our study. In a study by Hak et al severe pre-eclampsia was found in $40 \%$ of the cases. ${ }^{3}$ Depending on the severity of the maternal and foetal condition, delivery was planned. $51.8 \%$ underwent Caesarean section and $48.2 \%$ delivered vaginally (Table 6). In a study by $\mathrm{Hak}$ et al $46.4 \%$ underwent $\mathrm{LSCS}^{3}$ In a study by Anupama et al $42.8 \%$ underwent LSCS. ${ }^{11}$ In our study, the major indication for LSCS was foetal distress, with other contributing factors being pathological NST and abnormal Doppler.

In our study, the maternal complications were antepartum eclampsia (11.4\%), HELLP syndrome $(8.7 \%)$, abruptio placenta $(7.9 \%)$, pulmonary oedema $(2.6 \%)$ and DIC $(1.7 \%)$ (Table 5). There was no maternal mortality.

Serum LDH level was >600 IU/1 in $16.7 \%$ and <600 IU/1 in $83.4 \%$ (Table 7 ).

In our study $54.4 \%$ of the new born were shifted to NICU and $39 \%$ had FGR (Table 9). In a study by Hall et al, $40.4 \%$ were shifted to NICU. ${ }^{18}$ In our study, $7 \%$ of the patients presented with IUFD, 7\% had still birth. 7\% had neonatal mortality. $49.1 \%$ of the new born were $<1.5 \mathrm{~kg}, 42.7 \%$ were between $1.5-2.5 \mathrm{~kg}, 8.8 \%$ were $>2.5 \mathrm{~kg}$ (Table 8 ).

In our study, serum LDH was $>600 \mathrm{IU} / \mathrm{L}$ in $16.7 \%$ of the patients. HELLP syndrome was seen in $8.7 \%$ with $\mathrm{p}$ value 0.001 which was statistically significant (Table 10). This was similar to a study by Hak et al where HELLP syndrome was seen in $6.9 \% .^{3}$ Urvashi et al reported HELLP syndrome around $9 \%{ }^{8}$

DIC was seen in $1.7 \%$ of our patients and correlated with serum LDH level >600 IU/l with p value 0.004 which was statistically significant. Urvashi et al reported similar findings. ${ }^{8}$

Pulmonary oedema was seen in $2.6 \%$ of our patients and correlated with $\mathrm{p}$ value of 0.072 which was statistically significant.

In our study with serum LDH >600 IU/1 the patients had serum creatinine between $0.71 \mathrm{mg} / \mathrm{dl}$ with $\mathrm{p}$ value of 0.001 which was statistically significant. The other parameters like urine albumin, platelet count also correlated with increased serum LDH levels.

The incidence of FGR was $39.1 \%$ in the present study and $84.2 \%$ were in the group with serum LDH $>600 \mathrm{IU} / 1$ and $p$ value $<0.001$ which was significant.

NICU admissions and APGAR score $<7$ at 5 min were also more in the group with LDH>600 IU/1 which was statistically significant.
Mean AST and ALT values were higher in the group with $\mathrm{LDH}>600 \mathrm{IU} / 1$ with $\mathrm{p}$ value $<0.001$ which was significant.

There was no maternal mortality in our study.

\section{Limitations}

Investigations for thrombophilia were not done.

\section{CONCLUSION}

Pre-eclampsia is a multisystem disorder which is specific to pregnancy and has multifactorial etiology. Preeclampsia is associated with complications and can increase both maternal and perinatal morbidity and mortality. Elevated LDH levels correlated with maternal complications like HELLP syndrome, DIC, Pulmonary edema, thrombocytopenia and renal failure. Elevated LDH level correlated with fetal complications like FGR, APGAR <7 at $5 \mathrm{~min}$ and NICU admission. Serum LDH is a useful biochemical marker and can be monitored to prevent complications in preeclampsia, hence leading to a better outcome for both mother and the newborn.

\section{ACKNOWLEDGMENTS}

Authors are thankful to M. S. Ramaiah Medical College and Hospitals for their support during the study.

Funding: No funding sources

Conflict of interest: None declared

Ethical approval: The study was approved by the Institutional Ethics Committee

\section{REFERENCES}

1. Marlene MC. William's Obstetrics. 24th ed. Doctorlib; 2014: 728-770.

2. Vinitha PM, Chellatamizh M, Padmanaban S. Role of serum LDH in pre-eclampsia as a prognostic factor- a cross sectional case control study in tertiary care hospital. Int J Repord Contracept Obstet Gynaecol. 2017;6:595-8.

3. Hak J, Nisa NU, Gupta S. LDH levels in pregnancy and its association with severity of the disease and feto-maternal outcome in pre-eclampsia and eclampsia. JK Sci. 2015;17(3):110-3.

4. Gupte S, Wagh G. Preeclampsia-eclampsia. J Obstet Gynaecol India. 2014;64(1):4-13.

5. Petla LT, Chikkala R, Ratnakar KS, Kodati V, Sritharan V. Biomarkers for the management of preeclampsia in pregnant women. Indian J Med Res. 2013;138(1):60-7.

6. He S, Bremme K, Kallner A, Blombäck M. Increased concentrations of lactate dehydrogenase in pregnancy with preeclampsia: a predictor for the birth of smallfor-gestational-age infants. Gynecol Obstet Invest. 1995;39(4):234-8.

7. Qublan HS, Ammarin V, Bataineh O, Shraideh Z, Tahat Y, Awamleh I, Khreisat B, et al. Lactic 
dehydrogenase as a biochemical marker of adverse pregnancy outcome in severe pre-eclampsia. Med Sci Monit. 2005;11(8):393-7.

8. Sharma U, Hariharan C. Maternal and outcome in PIH patients in relation with serum LDH levels. IOSR J Dent Med Sci. 2017;16(1):1-4.

9. Bera S, Gupta S, Saha S, Kunti S, Biswas S, Ghosh D. Study of Liver Enzymes Especially Lactate Dehydrogenase to Predict Foetal Outcome in Pregnancy Induced Hypertension. Scholar's J Applied Med Sci. 2014;2(5):1569-72.

10. Walker JJ. Pre-eclampsia. Lancet. 2000;356(9237):1260-5.

11. Dave A, Maru L, Jain A. LDH (Lactate Dehydrogenase): A Biochemical Marker for the Prediction of Adverse Outcomes in Pre-eclampsia and Eclampsia. J Obstet Gynaecol India. 2016;66(1):23-9.

12. Jaiswar SP, Gupta A, Sachan R, Natu SN, Shaili M. Lactic dehydrogenase: a biochemical marker for preeclampsia-eclampsia. J Obstet Gynaecol India. 2011;61(6):645-8.

13. Doddamani UG, Doddamani GB. Perinatal Outcome in Pre-Eclampsia: A Prospective Study. Sch J App Med Sci. 2014;2(1):291-3.

14. Aziz R, Mahboob T. Relation between preeclampsia and cardiac enzymes. Atheroscl J. 2008;4(1):29-32.
15. Umastayasri Y, Vani I, Shamita P. Role of LDH (Lactate Dehydrogenase) in preeclampsia-eclampsia as a prognostic marker: An observational study. Int Arch Integrat Med. 2015;2(9):88-93.

16. Hazari NR, Hatolkar VS, Munde SM. Study of Serum Hepatic Enzymes in Preeclampsia. Int J Current Med App Sci. 2014;2(1):1-8.

17. Agrawal S, Walia GK. Prevalence and risk factors for Preeclampsia in Indian women: a national crosssectional study. South Asia network for chronic disease. Public Health Found India. 2014;1-23.

18. Hall DR, Odendaal HJ, Kirsten GF, Smith J, Grové D. Expectant management of early onset, severe preeclampsia: perinatal outcome. BJOG. 2000;107(10):1258-64.

19. Seed PT, Chappell LC, Black MA, Poppe KK, Hwang YC, Kasabov N, et al. Prediction of preeclampsia and delivery of small for gestational age babies based on a combination of clinical risk factors in high-risk women. Hypertens Pregnancy. 2011;30(1):58-73.

20. Townsend R, Brien P, Khalil A. Current best practice in the management of hypertensive disorders in pregnancy. Integr Blood Press Control. 2016;9:79-94.

Cite this article as: Vyas NP, Gopalakrishna N, Fernandes J. Serum lactate dehydrogenase level in pre-eclampsia and its correlation with maternal and fetal outcome. Int J Reprod Contracept Obstet Gynecol 2021;10:4107-12. 